\title{
Cultural adaptation and validation of the Brazilian Version of the Patient Activation Measure-22 items
}

\author{
Adaptação cultural e validação da versão brasileira do Patient Activation Measure-22 itens \\ Adaptación cultural y validación de la versión brasileña de Patient Activation Measure22 ítems
}

\section{Cristiane Martins Cunha', Eliane Nepomuceno', Rafaela de Oliveira Manzato', Débora Cristine Prévide Teixeira da Cunha', Dirceu da Silva", Rosana Aparecida Spadoti Dantas' \\ ' Universidade de São Paulo, School of Nursing of Ribeirão Preto. Ribeirão Preto, São Paulo, Brazil. \\ " Universidade de Campinas, Faculty of Education. Campinas, São Paulo, Brazil.}

How to cite this article:
Cunha CM, Nepomuceno E, Manzato RO, Cunha DCPT, Silva D, Dantas RAS. Cultural adaptation and validation

of the Brazilian Version of the Patient Activation Measure-22 items. Rev Bras Enferm [Internet]. 2018;71(4):1891-8.

DOI: http://dx.doi.org/10.1590/0034-7167-2016-0470

\section{Submission: 10-03-2016 Approval: 07-23-2017}

\begin{abstract}
Objective: To adapt and validate the Patient Activation Measure (PAM22) in a sample of Brazilians with chronic diseases under outpatient monitoring. Method: Adaptation process comprises translation, back translation, analysis by a committee of judges, semantic analysis, and pre-test. Psychometric validation was performed with 513 individuals. Construct validity was analyzed through Pearson's correlation, Student's t-test and Structural Equation Modeling; reliability was assessed by the intraclass correlation coefficient and Cronbach's Alpha. Results: The internal consistency was adequate and test-retest reliability was low to moderate $(p<0.05)$. Validity evidence was found on the convergent construct, with statistically significant correlations between measures of activation, self-esteem, anxiety, depression, and health status. The one-dimensionality of the theoretical model was not confirmed in the adapted version. Conclusion: Results have shown that the adapted version is reliable and valid, although the theoretical model cannot be explained in a single dimension.
\end{abstract}

Descriptors: Chronic Disease; Validation Studies; Self-Care; Clinical Management; Public Health.

\section{RESUMO}

Objetivo: Adaptar e validar o Patient Activation Measure (PAM22) em uma amostra de brasileiros com doenças crônicas, em acompanhamento ambulatorial. Método: A adaptação consistiu em tradução, retrotradução, análise por comitê de juízes, análise semântica e pré-teste. A validação psicométrica foi realizada com 513 indivíduos. A validade de constructo foi analisada pela correlação de Pearson, teste t de Student e modelagem de equações estruturais e confiabilidade pelo coeficiente de correlação intraclasse alfa de Cronbach. Resultados: A consistência interna foi adequada e a confiabilidade teste-reteste foi de fraca a moderada $(p<0,05)$. Encontrou-se evidências da validade de constructo convergente, com correlações estatisticamente significantes entre as medidas de ativação, autoestima, ansiedade, depressão e estado de saúde. A unidimensionalidade do modelo teórico não foi confirmada na versão adaptada. Conclusão: Os resultados evidenciaram que a versão adaptada é confiável e válida, embora o modelo teórico não seja explicado em uma única dimensão.

Descritores: Doença Crônica; Estudos de Validação; Autocuidado; Gerenciamento Clínico; Saúde Pública.

\section{RESUMEN}

Objetivo: Adaptar y validar el Patient Activation Measure (PAM22) en una muestra de brasileños con enfermedades crónicas y en seguimiento ambulatorio. Método: El proceso de adaptación consistió en traducción, retrotraducción, análisis por comité de jueces, análisis semántico y pre-test. Se realizó la validación psicométrica con 513 personas. La validez de constructo fue analizada por la correlación de Pearson, prueba t de Student y modelado de ecuaciones estructurales y confiabilidad por el coeficiente de correlación intraclase y alfa de Cronbach. Resultados: la consistencia interna fue adecuada y la confiabilidad testretest fue de débil a moderada $(p<0,05)$. Se encontró evidencias de la validez de constructo convergente, con correlaciones estadísticamente significativas entre las medidas de activación, autoestima, ansiedad, depresión y estado de salud. La 
unidimensionalidad del modelo teórico no fue confirmada en la versión adaptada. Conclusión: Los resultados mostraron que la versión adaptada es confiable y válida, aunque no se explica el modelo teórico en una sola dimensión.

Descriptores: Enfermedad Crónica; Estudios de Validación; Autocuidado; Gestión Clínica; Salud Pública.

\section{CORRESPONDING AUTHOR Rosana Aparecida Spadoti Dantas E-mail: rsdantas@eerp.usp.br}

\section{INTRODUCTION}

Within the framework of world public health, the active participation of the individual in the own health care becomes increasingly important. Studies have shown that practices encouraging health self-management lead to improvements in the perceived health status, healthy behavior, and reduces the number of hospitalizations in patients with chronic diseases. Activation is the degree of knowledge, ability, and confidence of the individuals in self-managing and performing health-related care, according to his/her perceived capacity ${ }^{(1)}$.

Such concept has been widely used in Australia, Europe, and the United States due to its importance to the clinical are and to the management of public health. It starts from the assumption that individuals with higher levels of activation are more likely to follow the treatment proposed and has more initiative to adopt healthy behaviors to self-manage their own health (e.g. performs preventive care, follows a balanced diet, and practices physical activities). In addition, these individuals are more proactive in seeking information about their medical conditions to improve their health ${ }^{(2)}$.

Many benefits come from the self-management of health in patients with chronic diseases. Among them, we can cite a higher adherence to treatment ${ }^{(3-5)}$, improved functional capacity quality of life $\mathrm{e}^{(5-6)}$, and better self-efficacy and emotional state ${ }^{(6-7)}$.

To assess the activation level of healthy or chronically ill individuals, the instrument "Patient Activation Measure" (PAM) was created in the United States, in a version with 22 items (PAM22) ${ }^{(8)}$. Posteriorly, this version was reviewed and shortened to 13 items $\left(\right.$ PAM13) ${ }^{(1)}$. Both measure the activation level of individuals regarding knowledge, ability, and confidence to self-manage and perform health-related $\operatorname{care}^{(8)}$. The theoretical model of PAM established the one-dimensionality of the instrument, regardless of its version ${ }^{(1,8)}$, in the measurement of the construct "activation". Such construct consists of four latent variables that are in the activation levels: Level 1 - Beliefs; Level 2 - Knowledge; Level 3 - Confidence; Level 4 Behavior. The items are hierarchically arranged according to the four activation levels, established based on beliefs, knowledge, capacity, confidence, and ability of the individual to present healthy behaviors. People with chronic diseases go through the four activation levels until they can be completely active in the management of their own health ${ }^{(8)}$. The use of PAM should be during the clinical interview, through an interventionist approach, based on motivational interview principles and the self-determination theory. This instrument can be used as a tool to guide the clinical approach of nurses. both in practice as in research.

\section{OBJECTIVE}

To adapt and validate the PAM22 in a sample of Brazilian patients with chronic diseases under ambulatory clinical monitoring.

\section{METHOD}

\section{Ethical aspects}

A methodological study, approved by the Research Ethics Committee of the School of Nursing of Ribeirão Preto, University of São Paulo. After presenting the research objectives and through proper clarification, the participant's agreement was requested, with the signature of an Informed Consent Form.

The author's permission was requested to perform cultural adaptation and psychometric evaluation of PAM22. Such authorization was granted and registered in a contract between the Brazilian researchers and the company responsible for the PAM copyright, the Insignia health (http://www.insigniahealth. com) since this permission was required to access and adapt the Brazilian version of the PAM22.

Cultural adaptation and psychometric validation processes

The methodological procedure followed carefully the steps used by international ${ }^{(9-10)}$ and national ${ }^{(11-12)}$ authors: 1 - Translation of the original version into Brazilian Portuguese; 2 - Achievement of the first consensual version in Portuguese; 3 - Evaluation, by a committee of judges, of semantic, idiomatic, cultural, and conceptual equivalency between original and the consensual version in Portuguese; 4 - Back-translation of the second consensual version in Portuguese into the original language and submission to the authors; 5 - Obtainment of the third consensual version in Portuguese, through comparisons between back-translated and original versions performed by the translators and researchers, added to the suggestion of the original authors; 6 - Semantic analysis of the items by a group of individuals of the target population (20 participants); 7 - New semantic analysis by another group of 20 participants; 8 - Pre-test (20 participants); and 9 - Psychometric evaluation of the final consensual version of the PAM22 (513 participants, including the 20 participants from step 8).

The step of semantic analysis was conducted with individuals of the study's target population, i.e. adults with chronic health conditions under monitoring in an ambulatory clinic of a university hospital, to verify the items' understanding by these individuals. Semantic analysis has been recommended and used in cultural adaptation studies carried out in Brazil, even after the semantic equivalence analysis is carried out by the judging committee, because it allows the possible participants to express their opinion on the clarity of items and answer scale ${ }^{(11-12)}$.

The final adapted version was applied to a sample of individuals with chronic diseases and underwent psychometric testing to evaluate validity (convergent construct, by known groups and dimensionality) and reliability properties (internal consistency by Cronbach's Alpha and test-retest reliability) of the adapted version. In addition, the dimensionality was assessed through confirmatory factor analysis associated with path 
analysis (structural equation modeling). As it was not necessary to perform further changes in the instrument, after the pre-test the 20 participants of this step were re-inserted into the final sample of the study, thus amounting to 513 participants.

\section{Participants}

For this study, we selected adults (from 18 to 80 years of age), regardless of gender and ethnicity, diagnosed with chronic diseases of diverse etiologies for at least six months, under ambulatory monitoring in the Clinic Hospital of the Federal University of Uberlândia, Minas Gerais, Brazil, subsidized by the Unified Health System (UHS). Those who did not have cognitive conditions were excluded, which was evaluated by the discriminatory capacity and mental and psychic orientation that would enable them to respond the researchers' questions.

\section{Procedures}

Data was collected through an individual interview conducted by one of the researchers with each participant, held in a private environment, where he/she answered the instrument with socio-demographic and clinical data, in addition to the adapted versions of PAM22, Hospital Anxiety and Depression Scale (HADS) and Rosenberg Self-Esteem Scale (RSE). Participants' perception of health status was measured by a Visual Analogue Scale (VAS). Medical history data of the participants were also obtained from their medical records. The data collection on the psychometric validation stage occurred from July to December 2014.

\section{Data collection instruments}

\section{Socio-demographic and clinical information questionnaire}

The socio-demographic information collected were: gender, age (in full years), marital status, level of schooling (years of study), and monthly family income (in Reais). Clinical data investigated were: chronic disease (self-reported), medical diagnosis (reason for the outpatient appointment in the institution where the interview was conducted), time of diagnosis of the chronic disease, number of comorbidities in the medical record. For patient characterization according to the nature of the chronic disease, we considered the medical diagnosis that motivated the ambulatory referral on the day of the interview.

\section{Version adapted for Brazilian Portuguese of the Patient} Activation Measure (PAM22)

The instrument consists of 22 items evaluated by an ordinal scale with five response options: Strongly disagree (1 point), disagree (2 points), I agree (3 points), totally agree (4 points), and does not apply ( 0 points). The raw score is obtained by the sum of values indicated in the responses to each item and may range from 22 to 88 points. Such score is later converted in an activation score (from 0 to 100 points) according to the table of scores conversion of PAM ${ }^{(13)}$. Thus, the health professional or researcher obtains score and level of activation of a given individual, whereas higher scores correspond to higher activation for health $\operatorname{care}^{(8)}$.

\section{Perceived health status evaluation by Visual Analogue Scale (VAS)}

A 100-millimeter visual analogue scale (VAS) was used to evaluate the perceived health status of the participants. They were told to indicate, on the line drawn, the position of their health status at that moment, considering 0 as the worst imaginable health status and 100 as the better possible.

\section{Hospital Anxiety and Depression Scale (HADS)}

Anxiety and depressive symptoms were assessed by the Hospital Anxiety and Depression Scale (HADS), in its version adapted and validated for Brazil ${ }^{(14)}$, which consists of 14 multiplechoice questions with values ranging from zero to three. Seven items asses anxiety symptoms (HADS-Anxiety) and the other seven deals with depression (HADS-Depression). The sum of each subscale may range from 0 to 21 points, and the higher the value, the greater the presence of the symptoms evaluated ${ }^{(14)}$.

\section{Rosenberg Self-Esteem Scale (RSE)}

To evaluate self-esteem, the Rosenberg Self-Esteem Scale was used, in its version adapted for Brazil(15). Such scale consists of ten items that evaluate positive and negative feelings the individual has of himself/herself, whose answers are obtained by an ordinal 4-point scale ranging from one to four. For obtaining the total score, the sum of the answers should be made, after inverting the values of the five negative items. The possible score ranges from ten to 40, with higher values indicating more self-esteem.

\section{Statistical Analysis}

The collected data were processed with the software IBM Statistical Package for Social Sciences, version 21.0, and Smart$P L S$, version 2.0, bot run on Windows ${ }^{\circledast}$. Data descriptive analysis was performed, and the significance level of 0.05 was adopted for statistical tests.

Items' internal consistency was assessed through Cronbach's Alpha and the test-retest reliability, by the intraclass correlation coefficient (ICC). After 15 days, 50 patients of the sample responded again the adapted version of PAM22 (retest).

Convergent construct validity was verified by Pearson's correlation between activation (PAM22) and variable measures: perceived health status (VAS), self-esteem (RSE), symptoms of anxiety (HADS-Anxiety) and depression (HADS-Depression). The validity of the construct was also analyzed by the Known groups technique, comparing the averages of the PAM22 through Student t-test and ANOVA according to the variables: gender, age (18 to 29,30 to 59 , and more than 60 years of age), time of diagnosis of the chronic illness (up to two years and more than 2 years); and through the Pearson's correlation test, evaluating similarities between PAM22 total scores and the variables: number of self-reported comorbidities and number of diagnosed comorbidities in the medical record. Correlation values below 0.30 were considered of little clinical applicability, even if they had statistical significance; values between 0.30 and 0.50 were moderate, and over 0.50 had a strong correlation ${ }^{(16)}$.

Dimensionality of the adapted version of PAM22 was verified through confirmatory factor analysis, which is used when the researcher already has knowledge on instrument structure ${ }^{(17)}$. The 
hypotheses' test and the adjustment of the relationship between latent (activation) and observed variables (four activation levels) were verified by the structural equation modeling (SEM) technique, used as validity evidence of a measuring instrument construct. Parameters analyzed were average extracted variance (AEV) and the Fornell and Larcker criterion (or average explained variance). AEV is an important requirement for a proper model adjustment and is equivalent to the construct commonality (convergent validity). For a proper AEV adjustments, items with factorial loads (or Pearson's correlations) that presented the lowest values were gradually eliminated until all AEV were above $0.50^{(17)}$. Cronbach's Alpha and composite reliability were calculated to evaluate the model's reliability.

\section{RESULTS}

In the sixth step of the cultural adaptation of PAM22 (semantic evaluation), 20 participants were interviewed. Of these, 30\% stated the questions were of regular understanding and $45 \%$ reported to have difficulties to understand the scale of response of the instrument. Items 2, 5 and 9 were those that presented greatest difficulty of understanding, as they are long and contain more than one statement, making it necessary for the researcher to repeat the reading of these items. Another aspect noted was that the reading of items written in the first person of singular hindered the participant's understanding. Thus, a new wording was proposed for the 22 items and, later, authorized by the author of the original instrument. In the new wording, "I/Me" was replaced by "You", performing the required verbal adequacies. In addition to these changes, items 7, 9, 12, 17, 19, and 22 were changed, replacing some words by others of more popular use in the Brazilian Portuguese. A new semantic analysis (seventh step) was performed with other 20 patients in outpatient care. Like steps 3 and 5, the changes were specific and related to the removal of articles, placement of pronouns, and exchange of words, preserving the semantic, idiomatic, cultural, and conceptual equivalencies between versions. This step did not require changes; hence, this version was applied with the other data collection instruments to other 20 patients, during the pre-test stage. Without the need for changes in the instruments, the psychometric validation of the PAM22 started, consisting of 493 new interviews, amounting to 513 adults participating in the research. Socio-demographic and clinical features of these participants can be found in Table 1.

Most were female $(62 \%)$ with a mean age of 49.9 years $(\mathrm{SD}=$ 14.6). The mean time of formal schooling was $8.2(S D=4)$ years, and $55 \%$ attended only elementary school. Sixty percent of them were married or living in a stable union, $70.8 \%$ had a household income of up to two thousand Reais, and $58.9 \%$ did not exert occupational activities at the time of interview. The most frequent chronic diseases among them were: cancer (13.6\%), rheumatoid arthritis $(9.9 \%)$, diabetes mellitus $(9.7 \%)$, HIV/Aids (9.7\%), hypertension $(9.6 \%)$ and heart failure $(8.6 \%)$, some of them presenting more than one of these diagnoses in their medical records. The time of diagnosis of the chronic disease, which prompted the outpatient consultation on the day of the interview, was more than two years for $75 \%$ of the patients. They had, on average, 3.2 $(\mathrm{SD}=2)$ chronic diseases listed in their medical records, whereas the mean of self-reported diseases was $11.8(\mathrm{SD}=2)$ (Table 1).
Table 1 - Socio-demographic and clinical characteristics of the 513 individuals with chronic disease, met at the Clinic of the University Hospital, Universidade Federal de Uberlândia, Minas Gerais, Brazil, 2014

\begin{tabular}{ll}
\hline Characteristics & $\mathbf{n}(\%)$ \\
\hline
\end{tabular}

\section{Gender}

Female

Male

$318(62.0)$

ars) Average (SD)

$195(38.0)$

Age (in years) Ave
$18-29$

$30-59$

$49.9(14.6)$

$49(9.6)$

$326(63.5)$

$>60$

$138(26.9)$

Time of formal study (years) Average (SD)

$8.2(4.0)$

Schooling level

Elementary School
High School
Higher Education
Graduate studies

285 (55.5)

$162(31.5)$

54 (10.7)

$12(2.3)$

Marital status (Married/Consensual Union)

$309(60.2)$

Gross family income (Reais) average (SD)

Up to 1000.00

1000.01 to 2000.00

$866.77(1284.2)$

157 (30.6)

$206(40.2)$

Over 2000.00

$150(29.2)$

Occupation (Inactive)

$302(58.9)$

Diagnosis

Cancer
HIV/Aids
Rheumatoid Arthritis
Systemic Lupus Erythematosus
Crohn's Disease
Ulcerative rectocolitis
Diabetes mellitus
Obesity
Chronic Renal Insufficiency
Coronary insufficiency
Systemic arterial hypertension
Cardiac failure

$70(13.6)$

$50(9.7)$

51(9.9)

$35(6.8)$

$40(7.8)$

25 (4.9)

$50(9.7)$

$30(5.8)$

$28(5.5)$

$41(8.0)$

49 (9.6)

44 (8.6)

Time of diagnosis

Up to 2 years

$128(25.0)$

Over 2 years

$385(75.0)$

Number of diagnosed comorbidities Average (SD)

$3.2(2.0)$

Number of self-reported comorbidities Average (SD)

$11.8(2.0)$

The average response to the 22 items of PAM was 3.13 (SD = 0.20 ) and the median was 3 (interval between 1 and 4). Overall, the total distribution of answers tended to "totally agree" and "agree" (totaling 82\%). The average index of answers "does not apply" was $0.05 \%$. Total raw score ranged from 49 to 88 (median 67), with a mean of $68.6(\mathrm{SD}=9)$. The total activation score ranged from 37.8 to 110 , with median 57.5 and average $60.2(\mathrm{SD}=12.7$ ) (Table 2).

The internal consistency of the adapted version was adequate (Cronbach's Alpha $=0.86$ ). The test-retest reliability evaluation was performed through the reapplication of the adapted instrument 
in a subsample of 50 patients after 15 days. Through the intraclass correlation coefficient (ICC), we found that most items presented significant correlations, which ranged from weak to moderate $(r$ $=0.26$ to $0.64, \mathrm{p}<0.05)$. Only items 14 and $15(r=0.13$ and 0.23 , respectively) had no significant correlations ( $p>0.05)$.

Table 2 - Descriptive statistics of the 22 items and of the total score of PAM22 obtained in a sample with chronic patients, met at the Clinic of a University Hospital, Universidade Federal de Uberlândia, Minas Gerais, Brazil, 2014

\begin{tabular}{|c|c|c|c|c|}
\hline PAM 22 & Obtained interval & Median & Mean & $\mathrm{SD}^{\#}$ \\
\hline Item $1 *$ & $1-4$ & 4.0 & 3.6 & 0.6 \\
\hline Item $2 *$ & $1-4$ & 4.0 & 3.5 & 0.6 \\
\hline Item $3^{\#}$ & $1-4$ & 3.0 & 3.2 & 0.8 \\
\hline Item $4^{\#}$ & $1-4$ & 3.0 & 3.3 & 0.7 \\
\hline Item $5^{\#}$ & $1-4$ & 3.0 & 3.1 & 0.8 \\
\hline Item $6^{\#}$ & $1-4$ & 3.0 & 3.3 & 0.7 \\
\hline Item $7^{\#}$ & $1-4$ & 3.0 & 3.3 & 0.7 \\
\hline Item $8^{\#}$ & $1-4$ & 3.0 & 3.4 & 0.7 \\
\hline Item 9\# & $1-4$ & 3.0 & 3.1 & 0.7 \\
\hline Item $10^{\#}$ & $1-4$ & 3.0 & 3.1 & 0.9 \\
\hline Item $11^{\#}$ & $1-4$ & 3.0 & 3.1 & 0.8 \\
\hline Item $12^{\#}$ & $1-4$ & 3.0 & 3.0 & 0.8 \\
\hline Item $13^{€}$ & $1-4$ & 3.0 & 2.9 & 0.9 \\
\hline Item $14^{€}$ & $1-4$ & 3.0 & 3.1 & 0.7 \\
\hline Item $15^{€}$ & $1-4$ & 3.0 & 2.9 & 0.8 \\
\hline Item $16^{€}$ & $1-4$ & 3.0 & 2.9 & 0.9 \\
\hline Item $17^{€}$ & $1-4$ & 3.0 & 3.1 & 0.8 \\
\hline Item $18^{€}$ & $1-4$ & 3.0 & 3.1 & 0.7 \\
\hline Item $19 * *$ & $1-4$ & 3.0 & 2.8 & 0.9 \\
\hline Item $20 * *$ & $1-4$ & 3.0 & 3.1 & 0.8 \\
\hline Item $21 * *$ & $1-4$ & 3.0 & 2.9 & 0.9 \\
\hline Item $22^{* *}$ & $1-4$ & 3.0 & 2.8 & 0.9 \\
\hline Total raw score & $49,0-88,0$ & 67.0 & 68.6 & 8.9 \\
\hline Total activation score & $37,8-100$ & 57.7 & 60.2 & 12.7 \\
\hline
\end{tabular}

Note: *Level 1 of activation (Belief); \#Level 2 (Knowledge); €Level 3 (Confidence); **Level 4 (Behavior); $S D=$ Standard Deviation.

As for the evaluation of convergent construct reliability, a moderate positive correlation was obtained between activation and self-esteem measures $(r=0.45, p<0.001)$. A weak positive correlation was obtained between activation and perceived health status $(r=0.18, p<0.001)$. Weak negative correlations, although statistically significant, were observed between activation and anxiety $(r=-0.22, \mathrm{p}<0.001)$ and activation and depression $(r=-0.23, p<0.001)$. Regarding construct validity, according to the known group reference, weak positive correlations were found between activation measures and years of study ( $r=0.11, p=0.010)$ and number of self-reported diseases $(r=0.14, p<0.05)$. There was a slight negative correlation between activation and the number of diseases diagnosed $(r=-0.12, p<0.01)$. No statistically significant differences were found when comparing the mean scores of the Brazilian version of PAM22 with gender ( $p=0.52)$, age group (from 18 to 29,30 to 59 , and more than 60 years of age) $(p=0.25)$ and time of diagnosis (up to two years and more than two years) $(p=0.62)$.
According to results obtained by the SEM, no evidence of the maintenance of one-dimensionality of the adapted version of the PAM22 was detected. For the instrument to keep its onedimensional structure, items 3, 4, 5, 6, 11, 12, 15, 17, and 22 should be excluded. Regarding model reliability through SEM, the composite reliability and the Cronbach's Alpha found were satisfactory (values above 0.8 ) for the adapted version of PAM22.

\section{DISCUSSION}

This study dealt with results of the process of cultural adaptation and validation of the 22-item version of the Patient Activation Measure (PAM22) for Brazilian Portuguese, in an heterogenous samples of adults with chronic diseases. Research conducted in several countries have shown that PAM is an adequate, valid, and reliable instrument to be used in some chronic conditions ${ }^{(1,18-25)}$.

The sample was highly heterogenous regarding socio-demographic data, a characteristic which is recommended for the psychometric validation of a generic evaluation instrument of a given construct. Although in general the participants were in their 40s, there were many young individuals and some older people, near the 80 years of age. This feature was similar to other PAM validation studies ${ }^{(1,8,18-23)}$. A similar tendency was observed concerning the heterogenous distribution of educational level, with the presence of individuals with little schooling and others with higher education and even graduate studies. On the other hand, the gross family income of the group was relatively low (from R\$ 2000.00 up to two minimum wages), including 2/3 of the participants. In comparison with other PAM validation studies that included participants from developed countries, these characteristics of schooling and income of the Brazilian case were peculiar.

Most of the subjects had a time of diagnosis of the chronic disease over two years, suggesting they had some experience in living with their health conditions. Regarding other validation studies, their samples also included individuals with multimorbidity conditions, such as, for examples, the original ${ }^{(8)}$, Dutch $^{(19)}$, Hebrew ${ }^{(20)}$, German ${ }^{(22)}$, and Italian ${ }^{(23)}$ versions.

In the process of instrument validation, assessing the reliability is essential. An adequate internal consistency was obtained for the adapted version of the PAM22, with high values of Cronbach's Alpha. Similarly, high values were obtained in the composite reliability analysis, from SEM, which is considered a better indicator of reliability than the Cronbach's Alpha since it is not influenced by the number of items and the sample size, prioritizing indicators according to their individual reliability ${ }^{(17)}$. The intraclass correlation test (ICC) showed the items' stability (test-retest analysis). The values obtained indicated statistically significant correlations, of weak to moderate magnitude, except for items 14 and 15 . Hence, the Brazilian version of PAM22 presented similar results to the original version. Results obtained with the adapted version could not be compared to those presented by other already published validation studies that focused on the 13-item version.

Regarding the validity of the convergent construct, this study was the first to use an instrument which measures self-esteem 
to evaluate PAM22 validity. Moderate and statistically significant correlations were found between PAM22 scores and the Rosenberg Self-Esteem Scale (RES). Self-esteem is an important attribute of the individuals, which affects the motivation to health self-care and is related to the concept of self-efficacy. Motivation is an attribute that has been considered effective for behavior changes and health self-management ${ }^{(26)}$. The convergent validity of PAM22 was also teste in correlation with activation measure and with anxiety and depressive symptoms; however, only weak correlations were obtained. PAM13 validation studies that used different anxiety and/or depression measures had similar results when testing the instrument's convergent validity ${ }^{(6-7,20,27)}$. Self-perception of health status also has a theoretical relationship with the activation construct ${ }^{(8)}$. It is noteworthy that activation measures and perceived health status was a weak correlation in the sample studied, which can be attributed to the one-dimensional measure chosen, i.e. the VAS. Other researchers have used the SF-12 $2(2,20,22,28)$ and the first item of SF$36^{(5)}$ and found an association between perceived health status and PAM13 ${ }^{(6,8,20,28)}$, reinforcing the assumption that individuals with better perceived health status are also more activated.

Concerning the search for construct validity evidence by the known groups technique, the results confirm the hypothesis that there was no relationship between activation, gender, and age of the participants. However, the hypothesis of the existence of a correlation between activation and time of diagnosis of the chronic disease has not been confirmed by this study $(r=0.05, p=0.12)$.

When evaluating the structural model of PAM22 through structural equations modeling, the results showed that the theoretical one-dimensionality of the instrument did not remain in the adapted version. For the PAM22 to keep its one-dimension structure, all the AEV values should be above 0.50. Thus, for obtaining a one-dimensional model, nine of the 22 original items would have to be excluded: 3, 4, 5, 6, 11, 12, 15, 17 and 22. Such result suggested that these items were not relevant or not part of the construct in the sample studied, and that the Brazilian version of PAM would have at least two factors. An important aspect to emphasize is that the one-dimensional version generated did not contain the thirteen items that make up the shortened version of the instrument, the PAM $13^{(1)}$.

\section{Study limitations}

The psychometric testing of the adapted version of PAM22 in only one site may be considered a study limitation by some psychometrists. It should be noted, however, that this version was responded by a significant number of participants (513 adults diagnosed with one or more chronic diseases) monitored in a teaching hospital in the countryside of Minas Gerais, with characteristics that are similar to most patients cared for in university hospital, subsidized by the Unified Health System. Another important aspect is that data was collected by interviews, ensuring the absence of blank responses due to lack of understanding or oblivion. These features of the study are important since validity and reliability are not fixed properties of a measuring instrument, but a result of the interaction between instrument, groups to be analyzed, and conditions involved in the data collection ${ }^{(29)}$. Therefore, the PAM22, as well as is shortened version, should be analyzed in other groups of individuals (without chronic diseases, higher schooling level or monthly income, different age groups) and by the use of other strategies (self-filling of the instrument, via internet, among others), so that more evidence are obtained about the investigation of the construct 'activation' on the Brazilian population.

Contributions to the field of nursing, health, or public policies The provision of the PAM22 should contribute to the nursing research, teaching, and care focused on the significant portion of the Brazilian population of individuals with chronic diseases and cared for in university hospitals linked to the Unified Health System. In the context of public policy, the active participation of the individuals with chronic health conditions is already one of the pillars of models of care to chronic diseases that are being proposed for the Brazilian health care system. Thus, assessing the level of activation of a given individual has been a tool in clinical management used by health professionals of other countries, and might be also used in Brazil to improve the decision-making process of the health team, focusing on each patients' care. Given this, it is recommended that other authors use the PAM22 in their research using other external criteria, to evaluate more widely the construct validity and it is suggested that the PAM22 is used to guide the clinical approach in interventional studies and clinical research.

\section{CONCLUSION}

Results obtained suggest that the adapted version of PAM22 for Brazilian Portuguese kept the reliability (internal consistency of the items and test-retest stability) of the original version. Validity evidence was found on the convergent construct by the achievement of statistically significant correlations between measures of activation, self-esteem, anxiety, depression, and health status. The theoretical model tested by SEM did not confirm the one-dimensionality of the PAM22 in the sample studied, suggesting the existence of at least two factors.

\section{FUNDING}

CAPES - Coordination of Higher Education and Graduate Training.

\section{REFERENCES}

1. Hibbard JH, Mahoney E, Stockard J, Tusler M. Development and testing of a short form of the patient activation measure (PAM). Health Serv Res[Internet]. 2005 [cited 2016 Oct 16];40:1918-30. Available from: http://www.calquality.org/storage/documents/me teor/1.2.5DevelopmentTestingShortFormPAM_Hibbardetal.pdf

2. Fowles JB, Terry P, Xi M, Hibbard J, Bloom CT, Harvey L. Measuring self-management of patients' and employees' health: Further 
validation of the Patient Activation Measure (PAM) based on its relation to employee characteristics. Patient Educ Couns[Internet]. 2009 [cited 2016 Nov 20];77(1):116-22. Available from: http://www.pec-journal.com/article/S0738-3991(09)00094-9/pdf

3. Mosen D, Schmittdiel J, Hibbard JH, Sobel D, Remmers C, Bellows J. Is patient activation associated with outcomes of care for adults with chronic conditions? J Ambul Care Manag[Internet]. 2007 [cited 2016 Oct 16];30:21-29. Available from: https://pdfs. semanticscholar.org/eae3/12ef0fdab0a3882a5b015b6f7409699c7d5e.pdf

4. Skolasky RL, Mackenzie EJ, Wegener ST, Riley LH. Patient activation and adherence to physical therapy in persons undergoing spine surgery. Spine [Internet]. 2008 [cited 2016 Oct 16];33(21):E784-E791. Available from: https://www.ncbi.nlm.nih.gov/pubmed/18827683

5. Skolasky RL, Green AF, Scharfstein D, Boult C, Reider L, Wegener ST. Psychometric properties of the patient activation measure among multimorbid older adults. Health Serv Res[Internet]. 2011 [cited 2016 Sep 13];46(2):457-78. Available from: https://www. ncbi.nlm.nih.gov/pmc/articles/PMC3064914/

6. Stepleman L, Rutter M, Hibbard J, Johns L, Wright D, Hughes M. Validation of the patient activation measure in a multiple sclerosis clinic sample and implications for care. Disabil Rehabil[Internet]. 2010 [cited 2016 Oct 16];32(19):1558-67. Available from: http:// www.tandfonline.com/doi/abs/10.3109/09638280903567885

7. Skolasky RL, Mackenzie EJ, Riley LH, Wegener ST. Psychometric properties of the patient activation measure among individuals presenting for elective lumbar spine surgery. Qual Life Res[Internet]. 2009 [cited 2016 Oct 16];18:1357-66. Available from: https:// www.ncbi.nlm.nih.gov/pmc/articles/PMC3561629/

8. Hibbard JH, Stockard J, Mahoney ER, Tusler M. Development of the patient activation measure: conceptualizing and measuring activation in patient and consumers. Health Serv Res[Internet]. 2004 [cited 2016 Dec 12];39:1005-26. Available from: https:// www.ncbi.nlm.nih.gov/pmc/articles/PMC1361049/

9. Dantas RAS, Silva FS, Ciol MA. Psychometric properties of the Brazilian Portuguese versions of the 29- and 13-item scales of the Antonovsky's Sense of Coherence (SOC-29 and SOC-13) evaluated in Brazilian cardiac patients. J Clin Nurs[Internet]. 2014 [cited 2016 Oct 8];23(1-2):156-65. Available from: http://onlinelibrary.wiley.com/wol1/doi/10.1111/jocn.12157/full

10. Assunção FFO, Dantas RAS, Ciol MA, Gonçalves N, Farina Jr JA, Rossi LA. Reliability and validity of the body image quality of life inventory: Version for Brazilian burn victims. Res Nurs Health [Internet]. 2013[cited 2016 Oct 16];36:299-10. Available from: http://onlinelibrary.wiley.com/doi/10.1002/nur.21538/epdf

11. Guillemin F, Bombardier C, Beaton D. Cross-cultural adaptation of health related quality of life measures: literature review and proposed guidelines. J Clin Epidemiol[Internet]. 1993 [cited 2016 Oct 16];46:1417-32. Available from: https://www.ncbi.nlm.nih. gov/pubmed/8263569

12. Ferrer M, Alonso J, Prieto L, Plaza V, Monsó E, Marrades R, et al. Validity and reliability of the St George's Respiratory Questionnaire after adaptation to a different language and culture: the Spanish example. Eur Respir J[Internet]. 1996 [cited 2016 Nov 10];9(6):116066. Available from: http://erj.ersjournals.com/content/erj/9/6/1160.full.pdf

13. Insignia Health, Ilc. Patient Activation Measure (PAM): License Materials, 2009.

14. Botega NJ, Pondé MP, Medeiros P, Lima MG, Guerreiro CAM. Validation of hospital scale of anxiety and depression (HADS) in epileptic ambulatory patients. J Bras Psiquiatr. 1998;47(6):285-89.

15. Dini GM, Quaresma MR, Ferreira LM. Adaptação cultural e validação da versão brasileira da Escala de Autoestima de Rosemberg. Rev Soc Bras Cir Plast [Internet]. 2004[cited 2016 Oct 16];19(1):41-52. Available from: http://www.rbcp.org.br/imagebank/pdf/19-01-04pt.pdf

16. Ajzen I, Fishbein M. Understanding Attitudes and Predicting Social Behavior. Ed. Prentice-Hall: New Jersey, 1998.

17. Hair JF, Hult GTM, Ringle CM, Sarstedt M. A Primer on Partial Least Squares Structural Equation Modeling (PLS-SEM). Los Angeles: SAGE; 2014.

18. Moljord IE, Lara-Cabrera ML, Perestelo-Pérez L, Rivero-Santana A, Eriksen L, Linaker OM. Psychometric properties of the Patient Activation Measure-13 among out-patients waiting for mental health treatment: a validation study in Norway. Patient Educ Couns[Internet]. 2015 [cited 2016 Oct 16];98(11):1410-17. Available from: http://www.pec-journal.com/article/S0738-3991(15)00282-7/pdf

19. Rademakers J, Nijman J, Van Der Hoek L, Heijmans M, Rijken M. Patient activation in the Netherlands: translation and validation of the American short form Patient Activation Measure (PAM13). BMC Public Health[Internet]. 2012 [cited 2016 Oct 16];12:577. Available from: http://bmcpublichealth.biomedcentral.com/articles/10.1186/1471-2458-12-577

20. Magnezi R, Glasser S. Psychometric properties of the hebrew translation of the patient activation measure (PAM-13). PLoS ONE [Internet]. 2013 [cited 2016 Oct 16];9(11):e113391. Available from: https://www.ncbi.nlm.nih.gov/pmc/articles/PMC4239053/

21. Brenk-Franz K, Hibbard JH, Herrmann WJ, Freund T, Szecsenyi J, Djalali S, et al. Validation of the German version of the patient activation measure 13 (PAM13-D) in an international multicenter study of primary care patients. PLoS ONE [Internet]. 2013 [cited 2016 Oct 16];8(9):e74786. Available from: https://www.ncbi.nlm.nih.gov/pmc/articles/PMC3787015/pdf/pone.0074786.pdf

22. Zill JM, Dwinger S, Kriston L, Rohenkohl A, Härter M, Dirmaier J. Psychometric evaluation of the German version of the Patient Activation Measure (PAM13). BMC Public Health[Internet]. 2013 [cited 2016 Oct 16];13:1027. Available from: https://www.ncbi. nlm.nih.gov/pmc/articles/PMC4228438/pdf/1471-2458-13-1027.pdf

23. Graffigna G, Barello S, Bonanomi A, Lozza E. Measuring patient engagement: development and psychometric properties of the Patient Health Engagement (PHE) Scale. Front Psychol[Internet]. 2015 [cited 2016 Sep 10];6:274. Available from: https://www. 
ncbi.nlm.nih.gov/pmc/articles/PMC4376060/pdf/fpsyg-06-00274.pdf

24. Maindal HT, Sokolowski I, Vedsted P. Translation, adaptation and validation of the American short form Patient Activation Measure (PAM13) in a Danish version. BMC Public Health[Internet]. 2009 [cited 2016 Oct 16](9):209. Available from: https://www.ncbi. nlm.nih.gov/pmc/articles/PMC2712471/

25. Ahn $\mathrm{YH}, \mathrm{Yi} \mathrm{CH}$, Ham OK, Kim BJ. Psychometric properties of the Korean version of the Patient Activation Measure 13 (PAM13-K) in patients with osteoarthritis. Eval Health Prof[Internet]. 2015 [cited 2016 Oct 16];38(2):255-64. Available from: http://journals. sagepub.com/doi/pdf/10.1177/0163278714540915

26. Jung MJ, Jeong Y. Motivation and self-management behavior of the individuals with chronic low back pain. Orthop Nurs[Internet]. 2016[cited 2016 Oct 16];35(5):330-37. Available from: http://journals.Iww.com/orthopaedicnursing/Abstract/2016/09000/ Motivation_and_Self_Management_Behavior_of_the.11.aspx

27. Munce SEP, Straus SE, Fehlings MG, Voth J, Nugaeva N, Jang E, et al. Impact of psychological characteristics in self-management in individuals with traumatic spinal cord injury. Spinal Cord [Internet]. 2016[cited 2016 Oct 16];54(1):29-33. Available from: http:// www.nature.com/sc/journal/v54/n1/pdf/sc201591a.pdf

28. Green CA, Perrin NA, Polen MR, Leo MC, Hibbard JH, Tusler M. Development of the patient activation measure for mental health (PAM-MH). Adm Policy Ment Health[Internet]. 2010 [cited 2016 Oct 16];37(4):327-33. Available from: https://www.ncbi.nlm.nih. gov/pmc/articles/PMC3536445/pdf/nihms427997.pdf

29. Keszei AP, Novak M, Streiner DL. Introduction to health measurement scales. J Psychosom Res [Internet]. 2010 [cited 2016 Oct 16];68:319-23. Available from: http://www.jpsychores.com/article/S0022-3999(10)00011-5/pdf 